\title{
Design and the function of art
}

\author{
Anders Brix, \\ The Royal Danish Academy of Fine Arts, School of Architecture
}

\begin{abstract}
Western thought tends to categorically separate art from "mere" artefacts: The arts serve no function except for aesthetic contemplation, while artefacts are functional objects intended for a specific purpose.
\end{abstract}

This separation has caused some confusion as to the field of design, which may sometimes belong to either and at other times neither: not really art but not just utility. Thus the concept of design has fluctuated between the putative luxury of art and the practical necessity of technology. The beaux-art view saw design as an art form in its own right. Contemporary views, in contrast, tend to emphasize design's capacities for problem solving, innovation and the like- to the extent of turning design itself into a "mere tool" for economic growth.

This article examines how the art-artefact dichotomy, rooted in the notion of "function," permeates contemporary design discourse. Through discussion of two examples, it reveals some of the logical inconsistencies the dichotomy gives rise to.

Having demonstrated the shortcomings of such separation, it turns to discuss its origin in thought: Language separates, while things, as such, are whole. Further discussion of even more examples attempts to show how our perception of things is governed and directed by our discourses, and how this may cause us to overlook important features of both things in general and the potential of design in particular.

Keywords: art, the extended notion of design, problem solving, vision2020

The problem is not the problem. The problem is your attitude about the problem. - Jack Sparrow aka Johnny Depp, in Pirates of the Caribbean
Since the dawn of human civilization, makers of physical things have - at least from time to timeimbued their work with felt qualities and rich allusions beyond the demands of mere necessity. Whether out of personal inspiration or commissioned to do so, their works may have been culturally instrumental in expressing collective meaning; such works may have contributed to the celebrations of a ruler or a won battle, may have served to honor lost men or the gifts of nature, or may have expressed awe of imagined, heavenly worlds and belief in the savior. They may even have celebrated human life and work as such, and, in so doing, granted collective meaning to various tools and implements.

When, occasionally, ancient things of, perhaps, this sort are excavated from the earth, archaeologists believe to see cultural significance of and embodied inspiration in these objects, and they sometimes take them as nothing less than unmistakable signs of a developed, sophisticated culture-of civilization. In taking things as signs, we may say archaeologists read objects, and, as they often have no written material to turn to, things may in fact be their only source of knowledge. This does not leave archaeologists in the dark since, as Vilém Flusser reminds us, "(e)verything, particularly the science, politics, art and religion of (any culture), can be traced back to factory organization and the manufacture of pots" (Flusser, 1999). Indeed, meaning is part and parcel of our things and our tools. "Things embody goals, make skills manifest, and shape their users," says Mihaly Csikszentmihalyi, and continues:

Man is not only homo sapiens or homo ludens, he is also homo faber, the maker and user of objects, his self to a large extent a reflection of things with which he interacts. Thus objects also make and use their makers and users. (Csikszentmihalyi \& Rochberg-Halton, 1981, p. 1) 
Things are not just insignificant practicalities. Things are vehicles of existential meaning (Pallasmaa, 2010), and a thing is either useful (i.e., a tool; a 'mere' artefact) or culturally significant (i.e., a readable, meaningful artwork) depending on how we choose to see it. Sometimes, however, both properties are immediately legible from the attributes of the object itself. Consider for example the object depicted in figures 1, 2 and 3.

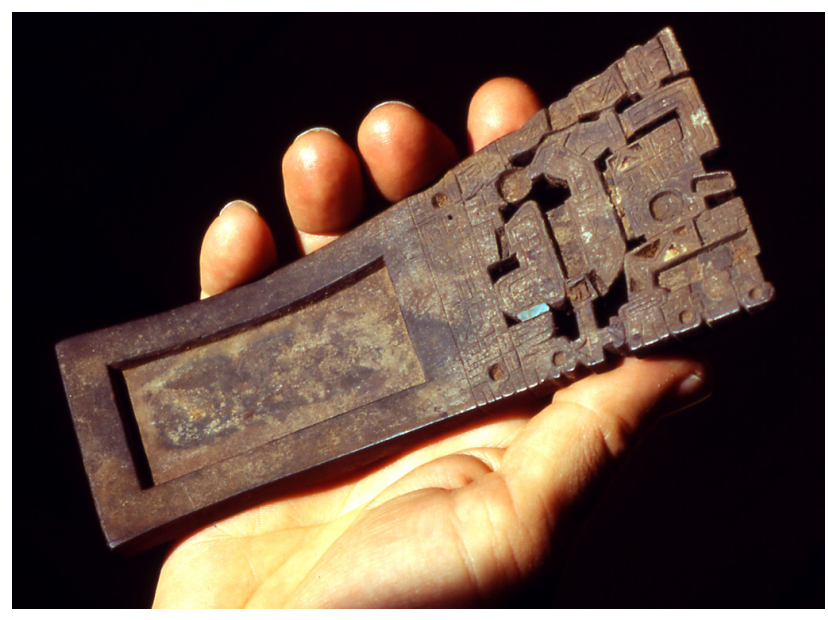

Figure 1
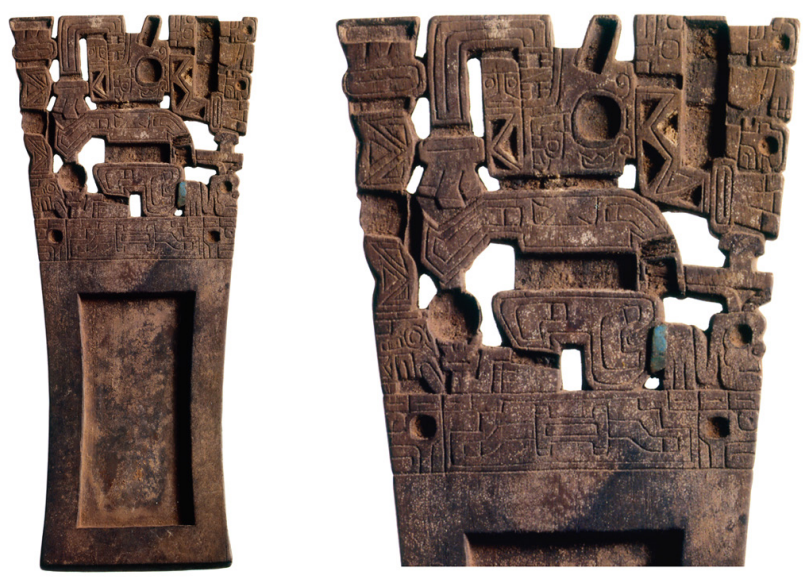

Figure 2 and figure 3 (all courtesy of C. Manuel Torres)

If you do not know what this object is, then all the better, because then you must agree-simply from looking at how it is articulated - that it seems to be both a practical object and an artwork. The delicacy put into the workmanship (not least of its upper part) suggests it a work of such devotion and imagery it might have been classified as art, had it been conceived and made in a context admitting this notion. On the other hand, since the lower part of the form seems to accommodate some substance or other object, it is just as clearly intended for some practical use. Incidentally, looking at the figurines that dominate the upper part of the object, it appears to belong to the inventory of some religious or mythological context; it is a thing to be appreciated in some foreign context of meaning and belief. The object shows features beyond mere necessity even though it obviously is a tool. Likewise, a Greek vase may be seen both as a tool for storing food and an object to be aesthetically appreciated. For historical reasons, however, modern culture tends to divide contemporary things into rather sharply divided categories: objects of purpose and objects of art, respectively.

The concept of art is a rather recent and entirely cultural construction. The word "art" is derived from Latin "ars" and Greek "techne," both terms originally denoting that, which is man-made and thus not nature. Not until the 18th century did "art" come to mean "fine art" and become a separate concept. The fine arts (beaux arts, the beautiful arts) were distinguished from arts in general (mechanical arts, crafts) by their purpose: The beaux-arts arts served the purpose of pleasure, while the arts served the purpose of utility. The core set of the fine arts comprised poetry, painting, sculpture, music and, interestingly, architecture (Shiner, 2001, p. 86), even though architecture served the dual purpose of being both practical and pleasurable (beautiful). Thus, from the very beginning, the separation of utilitarian purposes from purposes of pleasure and the very concept of "art" was somewhat ambiguous.

In the following, I wish to show how this superficial separation continues to haunt contemporary design discourse, and cause it largely to miss the point of design. I will discuss two examples: one concerned with strategies on how to develop the field of design in education and industry (meta level), and one concerned with fine distinctions between functional objects (detail level). Having demonstrated the shortcomings of the art-artefact dichotomy on both levels, I will in outline suggest how to restore that undivided view all cultures proceeding our own seem to have agreed upon.

\section{FORM GIVING AND PROBLEM SOLVING}

Since the outbreak of the comprehensive domination by technology known as the Industrial Age, the word "design" has (among other meanings) been used with reference to artistic molding of practical and useful artefacts. Worldwide, educations and institutions are based on a notion of design, which extends ancient traditions of craft and art into formalized, artistic education. Exemplary in this regard is, e.g., the 
Bauhaus. According to its founder, architect Walter Gropius, all the design disciplines, from architecture to jewelry, should be considered forms of art in their own right. "There is no essential difference between the artist and the craftsman," he stated in 1919 in the founding manifest (Shiner, 2001, p. 258). Design, so construed, largely means the art of form giving, but this art form does not isolate its object to indulge in visual pleasure, as some might have it. Rather, it is a holistic perspective in which the tool or artefact considered is studied, pondered, and tested in its every imaginable capacity, including its sensual, bodily appearance, its modes of functioning in practical context, and its inherent cultural meanings (e.g. "atmosphere," "expression" or "identity"). This integrated view, intrinsic to many schools of architecture and design, appears however to be fading, favoring instead a view with a narrow focus. As an example, let us consider the notions of design brought forward in "The Vision of the Danish Design 2020 Committee" (hereinafter referred to as "Vision $2020 ")$.

Vision 2020 is a Danish document on the politics of design. It is concerned with the significance of design in post-industrial society and offers recommendations on how design should be supported by and integrated in society in the future. In content and conceptions, Vision 2020 is in line with similar policies issued by other western countries as well as supranational bodies like the EU (Galle \& Brix, 2012). In its definition of design, Vision 2020 recognizes the above-mentioned foundation of design in art when it states that: "In its original sense, design means 'to give form.' As such, design has its roots in art" (Vision 2020, p. 11). While recognizing design as historically rooted in art, today, in contrast, Vision 2020 finds that design means something different:

In recent years, developments in the use of design have blurred the boundaries between design and a range of related activities. Design has come to mean more than giving form; it has increasingly become a strategic element in innovation processes... (Vision 2020, p. 6).

At first, this could seem to suggest an approach less categorical and more open than before. Design is now more than the art of form giving; it is a field with blurred edges, hardly distinguishable from a range of other activities. Thus this new and bigger design field is not something very specific. But, on the other hand, the lack of specificity is compensated by membership to some exclusive club of "strategic elements in innovation processes." The "more," it seems, follows from design becoming a "strategic element." But what does that mean? What is a strategic element anyway?

\section{According to the Oxford Advanced Learner's}

Dictionary, "strategic" means "forming part of a plan" and "for a particular purpose." Hence a strategic element may be anything that serves some kind of goal, some kind of specific purpose, some end. A strategic element, in other words, is a tool. So the revised and "extended" notion of design renders a conceptual change of major proportions, since, by this token, design is not of interest in and of itself anymore, but only in its capacity to reach goals. While the former notion saw design as the art of calling our physical world to life, so to say, Vision 2020 treats design as something merely instrumental. That the notion of design is hereby expanded is but a delusion. With the new notion, we can of course include more diverse kinds of stuff under the overarching concept of design: e.g., different kinds of intangible inquiry, mental structures symbolized in text or numbers, various diagrams, and even assorted post-it notes on a wall; anything, in fact, which might be instrumental in innovation processes. But the perspective applied to this bigger pool of stuff is in fact narrowed down, since design is now merely strategic, that is, in service of preconceived goals. The new notion of design may mean "more" in one sense, but all this "more" has a narrow, utilitarian concern. An art form is of course not expanded but, on the contrary, grossly reduced by being transformed into anyone's "strategic element."

The former notion of design — the "original" senseheld design and architecture a part of the fine arts system. In its origin, fine arts meant: for the purpose of pleasure in opposition to utility, and included only design of architecture. The notion of fine arts changed over the course of the years, variously conceived of as to serve purposes of "aesthetic experience," spiritual or moral teaching, or social liberation etc., and later, as is the case with Bauhaus, to include the crafts. In any case, the fine arts and design was always a field with high aspirations. The new and in fact reduced notion of design, on the contrary, confines design to be itself just a tool for obtaining prosaic goals. This tool, in turn, is a device to solve problems. Vision 2020 puts problem solving at the very heart of design when they say: "At its core, design identifies and solves problems in a creative and innovative way" (Vision 2020, p. 33).

That "problems" (as well as "innovation") are key concerns of design is a widespread notion. Sanders and Stappers, for instance, claim that in the future the 
field of design will have a completely new structure based on problems. Former days, they argue, held different primary categories of objects (furniture, clothing, architecture, etc.) and physical materials (textiles, ceramics, glass, etc.) as the structuring concepts of the field. This structure refers, of course, to the arts of giving physical form: design of this or that class of tangible objects. In the future, however, as design is "expanded" and problem-driven, and becomes largely immaterial, the goals of strategic processes will come to structure the field. Attention will turn away from what is being designed (the tangible objects), to focus instead on the problems (i.e., intangible discourse) design is deployed to solve. A new structure will emerge, based on design for this and for that: Design for interaction, design for transformation, design for sustainability, etc., and "design" will come to mean any activity in relation to such goals (Sanders \& Stappers, 2008, p. 5-18).

The idea, however, that design is fundamentally and in essence about "solving problems" itself poses a problem in bad need of a creative solution. This problem has to do with the ontological status of what we call "problems." We tend, namely, to presuppose that problems are things that exist, somewhat in the sense that a cup, a knife or a chair exists. But, as pointed out by Donald Schön, the formulation and framing of problems are the initial mental workings of the professional (Schön, 1984) and thus a product of the human mind. Problems do not exist. Problems are intangible or ethereal artefacts, and so roughly a member of the same logical category as deities. "Problems" belong to that framework of notions, which provide us with some sense of order in what is essentially messy, complex, real situations. Problems are not objective, factual conditions. They are conceptual skeletons, and since they necessarily favor only certain aspects of reality, problems are always reductions. Problems frame things a certain way, and in doing so they also imply solutions.

Therefore, problems are tools, and in this capacity themselves just a matter of design in the "extended" sense. To take the notion of problem solving to be essential to design therefore leaves us in a maelstrom of endless regress, since any problem is a design.

\section{ART AND PURPOSE}

Problem solving, that is, is too broad and generic a concept - or too blunt a tool, we may say - to be of any real use in defining design. Implicitly aware of this challenge, Vision 2020 takes a U-turn to look at design as a relative to art. After first claiming to expand design beyond art, to something more than art, namely in its essence problem-solving, Vision 2020 later says:

The designer shares the artist's ability to create-i.e., to develop something that has not been seen before. However, in contrast to the artist, the designer is bound to address a specific need or function. (Vision 2020, p. 11)

Unfortunately, this notion of art does not clarify much, but makes the situation even messier. It implies at least two problems. The first problem is that it can be neither a necessary nor a sufficient feature of art to have been 'never seen before'. It simply is not an essential ability of the artist. Does the portrait-painter, for example, not produce only more of something the world has in abundance already, namely portraits? You may argue that any portrait is not this portrait; that this special portrait has in fact never been seen before-that this portrait is unique. But that goes for your lunch too. Never before and never again will the world see this lunch. Any lunch is quite unique. Yet, I guess, it is not art. Something may well be new, but not art. And something may be art, yet not new. So it cannot be the 'newness' of neither the portrait nor the lunch that eventually make them art. It must be some other feature. Artness as such cannot reside in novelty, but has to dwell in something else.

The second problem (to which we will attend more closely) is the dichotomy that separates art from function. It is the current western conception of art, that of the "fine arts," chiefly from Kant (see, e.g., Thyssen, 2012, p. 421 or Davies, 2006, p. 5253), which tells us that art cannot serve functions external to itself. According to this view, art objects are objects intended for aesthetic appreciation only, and so cannot have any function or "interest" apart from this. In short, function corrupts art. The absence of function is what allows us to approach art aesthetically - with aesthetic attitude, that is - and hereby provide us with aesthetic experiences, which in turn are a special kind of experiences.

But does a painter, commissioned to paint the queen's portrait, not address a specific need or function? Or, to state the problem in a different way, why would anyone - say, the queen-commission an artist to do, e.g., tapestries if not to fulfill a need? And say the queen demands that the said tapestries fit the walls of her palace and depict the history of her nation. Does that not require the deliverables to function in a complex context? Indeed so. So art can in fact serve interests other than mere aesthetic contemplation. 
Moreover, depriving art of any "external interest" does not distinguish art as something obviously different from other human endeavors. We do many things that have no practical significance, simply for our own pleasure, well-being, curiosity and so on. Going to a concert or going to a football game lacks practical purpose to an equal degree. Yet concerts belong to the realm of art, whereas football games do not. Absence of function is therefore neither a necessary nor a specific property of art. It simply is not peculiar to art.

The Greek vase mentioned earlier, as well as the mysterious object of figures 1, 2 and 3 above, seem to exhibit a number of properties pertaining to fine art, just as does a long track record of religious (e.g., Christian, Islamic and Buddhist) artefacts. A number of non-western societies have not made clear distinctions between art and artefacts. The Balinese saying: "We have no art, we do everything the best way we can" captures this poignantly (as quoted in Saito, 2007, p. 41). Functional objects have at times even been found to work as part of the western fine-arts system. This has led to some confusion as to how a thing eventually acquires that "special meaning," which grants it status as art. What sorts of phenomena give rise to the pertaining "special kind of experience"? Is such affordance allowed by some essential property of the object? Is it perhaps rather a matter of the context of the object? Or is it determined by either the mode of attention of the beholder or the mode of intention of the producer?

In his essay “Vogel's Net” (Gell, 1996), Alfred Gell inspects the example of a fishing net retrieved from the African Zande tribe. In the context of the Zande people's hunter-gatherer life, the net is of course a functional object, indeed a very important one, since it is essential to food provision. But in the context of a gallery in New York City in 1988, displayed as an artwork, the net appears to possess all the features of an art object: rich in craftsmanship, invoking aesthetic presence and legible with different kinds of inherent meaning. It is tempting to conclude that this change of context (re-framing) is what has caused the status of the net to change: that in the context of the gallery we approach and read the net aesthetically, and thus alter its status from artefact to art. In the catalogue text, however, renowned art philosopher Arthur Danto claims that, strictly speaking, the net remains a mere tool, not a work of art, since, in the cultural context that crafted it, it was an object of utility. According to Danto, whether a thing belongs to art or non-art is not a matter of how the thing is framed. It is not a property of the object either. Rather, it is a matter of its symbolic significance in the cultural context of its production.

Danto explains his view by means of an experiment of thought, in which he imagines two separate tribes whom he calls the "pot people" and the "basket folk," respectively. Both tribes produce both pots and baskets. But since the tribes' cosmologies are different, the status of their objects is different. The pot people believe that god was a potter who turned the earth from clay. For the pot people, therefore, potters are the wise and holy men of the tribe, and their products are of great cultural significance. The pot people also make baskets, but these are only produced for utilitarian purposes, and, although fine craftsmanship, they remain mere artefacts. Over the hill, by the basket folk, things are different. Here God created the world by weaving it from grass, so for the basket folk basket makers are holy men producing objects of great significance. The basket folk also make pots. But pots are simply utilitarian objects, and, although being skilled craftsmen, potters enjoy no elevated position in society and their products no meaning apart from utilitarian purposes. Even though the pots of the pot people are indistinguishable from the pots of the basket folk, and the baskets of the basket folk indistinguishable from those of the pot people, for Danto, the pots of the pot people and the baskets of the basket folk are art, whereas the pots of the basket folk and the baskets of the pot people are artefacts. This is so because such is the status of these objects in their respective cultures.

Applied to the case of the fishing net, Gell points out; Danto's claim amounts to little more than the projection of his own separation onto Zande culture. For the Zandes, hunting is by no means simply the daily routine of "obtaining the staff of life" (Gell, 1996, p. 24), but on the contrary a profoundly meaningful and highly ritualized act. For them, the net is both art and artefact-or rather: these domains were never separate in the first place. In Zande culture, the net is a highly meaningful object precisely because it is essentially utilitarian. This, Gell shows, is generally the case with traps such as fishing nets and similar devices: they are symbolic and meaningful artefacts crafted with more care than what is technically required in order to fulfill their function. They are utilitarian objects. But they are also vehicles of gratitude for the gifts of nature, paying respect and honor to the prey. As such, they fall under Danto's account of art. And so, we may add, does for instance the works of the shakers, for whom all work was 
a sacrament, and every man-made object thus a celebration and tribute to God (Andrews \& Andrews, 1950).

The art-artefact dichotomy does not work very well around boundary conditions, it seems. Practical function on one side, and the symbolic significance and aesthetic contemplation associated with art on the other, are, at least in principle, not mutually exclusive concepts. You may think this is mostly an art-philosophical dispute relating to objects remote from our daily routines. Let us therefore turn to our own daily utilitarian artefacts. We shall see that also in this case, the concept of function fails to provide a solid ground for any art-artefact distinction.

\section{USE AND FUNCTION}

In a recent book, $A$ Theory of Craft - function and aesthetic expression, Howard Risatti attempts to develop a taxonomy of craft-objects, built on the concept of function. Risatti starts from fine arts, with thoughts much like those of Danto. Fine arts, Risatti says, serve the sole purpose of experience. In this respect, artworks are ends in themselves. They have no "real," practical function; their "function" is to convey and communicate meaning. Tools, on the other hand, are mechanically activated devices whose purpose it is to do something to another material in order to produce some other object. A knife, for instance, is made for cutting other things, not for its own sake. Thus it is not an end in itself. Craft objects stand between these two. Like artworks, but unlike tools, craft objects are not intended to make other things, and they need no mechanical activation to work. Yet, like tools, craft objects serve a function. Expanding on these distinctions, Risatti argues that craft objects can be found only among those objects that serve the purposes of either "covering," "containing" or "supporting" something. Blankets cover. Cups contain. Chairs support. These functions are not mechanical in the tool sense. These functions - and these alone-are purposes not intended to produce something other.

Risatti's distinctions are wisely thought out and carefully articulated. They leave one puzzled, though. Does not a cup have a number of functions, some of which are not less mechanical than those of other tools? Certainly the cup is a container, as it sits on the table containing tea, but a second later, lifting the cup to reach ones lips, the cup is a tool used to hoist the tea. Another second later, the cup is tilted by the hand, mechanically changing the shape of the tea to give it a large surface and a thin edge. This allows the lips to blow on the hot tea and gently let the tea run over the edge of the cup, into the mouth. In acting mechanically on the tea, the cup now serves the function of "pouring."

Risatti's taxonomy is based on the possibility of pointing to one fixed and singular function of any object. But, as we have seen, function is in fact an ambiguous concept. This ambiguity becomes even more apparent when we consider that in order for something to work, it must of course work for someone. But said someone is in a sense free to choose what use to put the thing to. Someone may throw his or her cup at me if I say something out of line. And I may turn my empty cup over, using it as a tool for drawing circles on a piece of paper. Things may serve a number of purposes and may be used in numerous ways, depending on what we see fit at the moment. So function is not simply a property of the object. It is as much a function of us, as famously pointed out by James Gibson (Gibson, 1986). Risatti's response to this problem is unequivocal: The function of an object is not the use someone puts it to. The function is that purpose, for which the maker intended the object. Although clear and straightforward, this does not help. The function is still not in the object, but in someone else. And-as is the case with the Zande fishing net as well as the object in figures 1, 2 and 3 - this someone may be far away and hard to find.

To say that the cup's function is "to contain" does not say anything essential or exhaustive about it. It rather frames it in a certain way; see only certain aspects of it.

\section{FRAMES AND CONTAINERS}

Vision 2020 appears to dissolve boundaries - such as those between design and other fields - but in fact it installs new ones. Although it claims to blur the edges between certain fields, in doing so it sees only a few of the properties pertaining to a class: it takes "creativity" to account for "art," "problemsolving" to account for "design," innovative ideas to be the "core" of design, function to be opposed to art and so on and so forth. Risatti, in turn, attempts to make words and concepts serve the specific purpose of categorizing, but his chosen conceptual container, function, is ambiguous and thus not a good tool for categorization. Vision 2020, we may say, frames design in a certain way (so as to see only its functional aspects. Risatti, on the other hand, wants concepts to contain (so as to divide decisively between different classes of physical objects). 
For Danto, it is not the design of the objects of the pot people or the basket folk that is important. It is how the two peoples frame their objects with their concepts. Gell, in turn, is able to unmask Danto's argument, revealing it as an attempt to contain the Zandes in Danto's own concepts.

Words and concepts, it seems, can be put to use in different ways (e.g., as either frames or containers). Words do not have fixed functions. Just like the tangible man-made objects Csikszentmihalyi \& Rochberg-Halton talk about, words also "make and use their makers and users." It may therefore be useful at this point to recapitulate - if only brieflywhat language is and how we use it. After all, the separation of art from artefacts is first and foremost the work of language.

We use language every day without thinking much about how it works. Like other tools we know well, it has become an integrated part of ourselves, so that when using it we overlook its mechanics: we do not attend to the words themselves, but rather to that on which the words may bear, as famously observed by Michel Polanyi (Polanyi, 1966). At face value, however, words are sounds. When using language, welargely unknowingly - ascribe a certain meaning to these sounds, so that for instance the sound of saying "chair" is symbolically connected to a tangible object in front of us. Tangible objects like chairs and cups have names ("chair" and "cup," respectively) somewhat like persons do. But most words are either derivative names (like "furniture" or "utensils") or concepts like, e.g., "god," "love," "function," and the like. Apart from the literal names of primary concepts, language structures our being-in-the-world through the use of metaphors, all of which can ultimately be traced back to our physical bodies and the sensing, somatic lives of ours (Lakoff \& Johnson, 1980). For example, we talk of time as motion ("time flies"), purposes as destinations ("he's not there yet"), knowing as seeing ("I see what you mean") and so on and so forth. These metaphors are not simply poetic whims or embellishment of expression. Since we think in and through language, these underlying metaphors form the very structure of our thinking. They are not figures of speech but cognitive cross-domain mapping (Malafouris, 2013, p. 62); they do not belong to the realm of words but the realm of thought (op. cit.)

According to Lakoff and Johnson, an objectivist tradition of (Western) philosophy tends to think of conceptual categories as were they containers (Lakoff \& Johnson, 1980, p. 210). Being sounds, concepts are of course not containers. It is our bodily experience of how real objects may be fitted in physical containers, which prompts us to think of categories as being like containers. We put things in(-to) this or that category. Risatti's taxonomy, for instance, uses the concept of function much in the same way a certain toy for small children is used. This toy consists of a number of containers, each with a differently shaped opening in the top. The triangular opening accepts the triangular blocks, the circular opening the cylindrical blocks etc. In order for objects belonging to design, craft and art, respectively, to pass only the opening of the container representing a certain set of properties - those pertaining to function-Risatti has to pick only one, or a few, of the multiple aspects and properties intrinsic to any object.

In order to (metaphorically) place an object in a category, we must pick from an endless row of possibilities those particular features we find to be the defining traits just now, in the given context, the given framework. To call anything something thus is a constructive act. And this act points simultaneously to features of the object and valences of our conceptual system. Risatti attempts to use words as were they tools, but his tools finally fail him because words may, metaphorically, perhaps cover or support, but cannot contain. Categories are in fact not so much like containers. Rather, they are open-ended and interactional (Lakoff \& Johnson, 1980, p. 119-124). A thing may at times be this and at other times that: a net a device for food or a gallery show piece, a cup an end in itself or a tool for pouring liquids. Language is not the sharp and precise tool we think it to be. Clear distinctions, so as to determine conclusively what distinguishes a work of art from a work of craft or a work of design, cannot exist. It is impossible to have art and artefacts separated in any decisive way.

If the categories of language fail to contain or frame the sets of properties that account for how objects are sorted into either artworks (to be aesthetically contemplated) or artefacts (to be practically used), what is it that determines whether we approach an object uninterestingly, aesthetically, or with the calm calculus of purpose?

\section{ATTITUDE}

A cup may be seen both as an end in itself and a tool for drinking tea. Art may be seen both an end in itself and a meaning-making tool, devised by the artist to make us, e.g., ponder existential questions, share religious feelings, or partake in the cultural coherence of a kingdom. On the other hand, if framed in a certain way, tools may be works of art: fishing nets and traps alike can go both ways, and since, in their 
own cultural contexts they may pertain to existential questions, religious feelings and cultural significance, they even fall under Danto's essentialist definition of art. Design, in turn, may be either a form of art or a tool for strategic purposes, depending on how it is framed, approached and categorized.

Whether we see something in its aesthetic-artistic or its practical-tool'ish capacity is not a matter of any one particular feature of the thing, but of how we approach it. We see the aesthetic appearance, the useful properties or the cultural significance of any thing according to what seems appropriate in the given context. When we walk in the gallery and know we see art, we acknowledge what we see as art; we see its appearance. The gallery frames our thinking, so to say. "The knowledge that what is before us has no practical significance in the world is what enables us to give attention to its appearances as such" (Langer, 1957, p. 49). In the workshop, by contrast, we may look at things only in search for their practical applicability to the task at hand. In short, before we actually see anything, we see the idea of art or the idea of tool, respectively, and we attend to our surroundings partly through that idea. "That we know what we see is no truer than we see what we know. Perception depends heavily on conceptual schemata" (Goodman, 1972, p. 142).

In the essay "Everyday Aesthetics of Embodiment," Richard Shusterman tells the story of a change in aesthetic import caused by a change in perspective. He had sat down to meditate in front of the beautiful panorama of a bay, wondering why someone had placed two rusty, old barrels partly blocking the view. After contemplating the beautiful spot, upon withdrawing from his meditation, he sees the barrels anew:

Turning my glance toward the closest of the two barrels, I discovered that my perception had awakened to a more penetrating level in which the ordinary ugly object was transfigured into something of breathtaking beauty, just as beautiful as the sea, indeed even more so. I felt I was now truly seeing that drum can for the first time, savoring the subtle sumptuousness of its coloring, the shades of orange, the tints of blue and green that highlighted its earthy browns. I thrilled with the richness of its irregular texture, its tissue of flaking and peeling crusts embellishing the hard iron shell, a symphony of soft and firm surfaces that suggested a delicious feuilleté. (Shusterman, 2013, p. 29)

Shusterman's perception "had awakened," as had it been sleeping, and he is allowed to see as "for the first time" the actual beauty of the barrels. Caused by this shift in his modality or awareness, he now looks at the barrels with the Kantian, aesthetic gaze: as he approaches them "uninterestedly," unframed, uninhibited by preconceptions, he now "truly" sees the barrels. Their "appearances as such" emerge. Furthermore, this leads him to see anew also something, which in everyday perception counts as aesthetic:

I realized that it was more the idea of the sea that I had been regarding as beautiful, not the sea itself, which I saw through a veil of familiar thoughts -its conventional romantic meanings and the wonderful personal associations it had for me, a Tel Aviv beach boy-turned-philosopher. The barrel, without losing its status as everyday object, in contrast, was grasped as a beauty of the most concrete and captivating immediacy. (Ibid., p. 29)

In the meditative quieting of language, Shusterman sees the barrels unconceptualized (or at least free from any immediate conception), but he also sees how his everyday perception of the sea is filtered through his conceptions of it. He sees the drums and the sea anew, but he also sees how his daily perception works through "a veil of familiar thoughts." We cannot help but see things through the veil of our familiar thoughts. We are caught in the web of our concepts.

\section{CLOSING REMARKS}

It is impossible to decisively separate art from artefacts. A fishing net may, by virtue of its very devotion to being an artefact, possess all the properties associated with art. The same can be said about any altarpiece. To the Balinese, the separation is artificial in the first place, and to the Shakers even unchristian. It is only the recent and local discourse of ours that insists on art and artefacts being disparate, mutually exclusive categories: either that which is conceived and made to be means to an end, or that which is made to express existential and collective meaning.

Having detached art from artefacts (and therefore art from design), art is left as that which is useless and without real function, relegated to entertainment, offhours and distraction, separated from daily life and from "real" meaning. By the same token, artefacts are reduced to their instrumental properties and design reduced to a blurred array of "strategic" activities like problem solving and innovation. 
Today, however, artefacts are not, per se, less meaningful than they have been at other times and in other places. It's just that we have acquired the habit of framing them less meaningfully. For Vision 2020, design has no significance in itself. It is a tool, a mere artefact, to be utilized to achieve ends. “When exploited to its fullest potential and used responsibly, design (broadly defined) can contribute considerably toward creating a better society," says Vision 2020 (on page 10). The metaphor structuring this proposition is one in which Vision 2020's broadly defined, but narrowly focused, notion of design is thought of as a field; a physical land area of scarcely explored, virgin land to be sown and harvested, indeed "exploited" to the "fullest," for the benefit of society. Design is thus both a tool (to be "used responsively") and a resource (to be "exploited"). Given Vision 2020's simplistic approach to design, it seems no coincidence that this metaphor brings to mind how colonization of remote areas as a matter of routine has been justified by potentials for wealth and affluence. While in the early days of the Industrial Age it was the plains and peoples of the planet being exploited, in the Postindustrial Age it is ideas.

It has been the aim of this article to draw attention to differences of attitude, i.e., to render the conception and design of artefacts as a spiritual matter of utmost importance, rather than a lifeless resource to be tapped. Given the poor state of our planet and the problems created by this messy situation, demands seem greater than ever that we consider artefacts part of meaning, the creation of artefacts part of meaning creation in general, and the results of such creation part of discourse in general. Art should embrace function, not the other way round, since function covers only some aspects of artefacts or art forms, whereas it is the office of art to concern itself with all aspects in unison. Such, we may say, is the function of art. Thus, the problem is not so much what design is or is not, or indeed that it ought to be something other than what it has always been. The problem is the reductive attitude of Vision 2020 and the discourse it is part of.

We must alter this veil of familiar thoughts.

\section{EPILOGUE}

You may ask what the thing in figures 1, 2 and 3 is? It is a snuff tray from the Amazonian jungle. The function of the tray is to contain the snuff. The function of the depicted deity is to frame the snuff. The function of the whole system - tray, snuff and deity-is to solve problems.

\section{REFERENCES}

Andrews, Edward Deming \& Andrews, Faith (1950). Shaker furniture. The craftsmanship of an American communal sect. New York: Dover.

Csikszentmihalyi, Mihaly \& Rochberg-Halton, Eugene. (1981). The meaning of things - domestic symbols and the self. Cambridge: Cambridge University Press.

Davies, Stephen. (2006). The philosophy of art. Oxford: Blackwell.

Flusser, Vilém. (1999). The shape of things. London: Reaktion Books.

Galle, Per \& Brix, Anders. (2012). Artistic Design in a Competitive World. Proceedings of Projecting Design 2012: Global Design Bridge. Cumulus Conference, Santiago.

Gell, Alfred. (1996). Vogel's net. Traps as artworks and artworks as traps. Journal of Material Culture, 1(1), 15-38. http://dx.doi. org/ 10.1177/135918359600100102

Gibson, James J. (1986). The ecological approach to visual perception. New York: Psychology Press.

Goodman, Nelson. (1972). Problems and projects. Indianapolis, IN: Bobbs-Merrill.

Lakoff, George \& Johnson, Mark. (1980). Metaphors we live by. Chicago: University of Chicago Press.

Langer, Susanne. (1957). Feeling and form: a theory of art. New York: Charles Scribner's Sons.

Malafouris, Lambros. (2013). How things shape the mind: a theory of material engagement. Cambridge, Mass: MIT Press.

Pallasmaa, Juhani. (2012). The existential task of architecture. In Peter MacKeith (Ed.), Encounters 2-architectural essays. Helsinki: Rakennustieto.

Polanyi, Michael. (1966). Tacit knowledge. Chicago: University of Chicago Press.

Risatti, Howard. (2007). A theory of craft-function and aesthetic expression. UNC Press.

Sanders, Elizabeth B. N., \& Stappers, Pieter Jan. (2008). Cocreation and the new landscapes of design. CoDesign, 4(1). http://dx.doi.org/ 10.1080/15710880701875068

Schön, Donald. (1984). The reflective practitioner. Basic Books.

Shusterman, Richard. (2013). Everyday aesthetics of embodiment. In Ritu Bhatt (Ed.), Rethinking aesthetics: the role of body in design. New York: Routledge.

Shiner, Larry. (2001). The invention of art-a cultural history. Chicago: The University of Chicago Press.

Thyssen, Ole. (2012). Det filosofiske blik. Informations Forlag.

The Vision of the Danish Design 2020 Committee. (2014).

Retrieved from http://erhvervsstyrelsen.dk/ visiondanishdesignpubl/0/7

\section{CORRESPONDENCE}

Anders Brix, The Royal Danish Academy of Fine Arts,

School of Architecture, Philip de Langes Allé 10, 1435

Copenhagen K, Denmark

E-mail: anders.brix@kadk.dk

Published online 30 December, 2015

ISSN 1749-3463 print/ISSN 1749-3471

http://dx.doi.org/10.14434/artifact.v3i4.12816

(c) 2015 Artifact 